\title{
Repensando la relación con la teoría a propósito de la obra de Paulo Freire
}

Rethinking the relationship with theory regarding Paulo Freire's work

\author{
J. Eduardo Sierra Nieto \\ e-mail: esierra@uma.es \\ Universidad de Málaga. España
}

Eduardo S. Vila Merino

e-mail: eduardo@uma.es

Universidad de Málaga. España

\section{Resumen}

La celebración del centenario del nacimiento del insigne pedagogo de Recife, Paulo Freire, nos convoca en este número Monográfico dedicado a pensar a propósito de su persona y su obra. En este artículo, que tiene como objetivo presentar el número (su sentido y su contenido), nos hacemos eco de la importancia de reivindicar el conocimiento teórico de la educación, apostando por reconectar con la obra de Freire como un autor clásico cuyo valor anida en la potencia de sus ideas, aún hoy.

Palabras clave: Paulo Freire; teoría; praxis; ética; tradiciones; esperanza

\section{Abstract}

The celebration of the centenary of the birth of the distinguished teacher from Recife, Paulo Freire, invites us in this special issue which is dedicated to thinking about him and his work. In this paper, which aims to present the number (its meaning and its content), we discuss the importance of claiming theoretical knowledge of education, supporting on reconnecting with Freire's work as a classical author whose value lies in the power of his ideas, even today.

Keywords: Paulo Freire; theory; praxis; ethics; traditions; hope

Recibido / Received: 23-06-2021

Aceptado / Accepted: 27-07-2021

Publicación en linea / Published online: 28-07-2021

Cómo referenciar este artículo / How to reference this article:

Sierra, J. E. \& Vila, E. S., (2021). Repensando la relación con la teoría a propósito de la obra de Paulo Freire. Tendencias Pedagógicas, 38, pp. 1-5. doi: 10.15366.tp2021.38.001. 


\section{Presentación}

Paulo Freire siempre tuvo clara la importancia del conocimiento teórico, la necesidad de ponerlo en contexto y de que la praxis se alimentase permanentemente de la reflexión crítica y de la ética. Por eso en el centenario de su nacimiento, y con una situación de crisis a nivel mundial agravada por la pandemia, consideramos fundamental releerlo, revisarlo y repensarlo a la luz de nuestra realidad; siempre convencidos de que su pensamiento es histórico (como él diría), sin duda, pero es que así es todo pensamiento teórico y así es toda puesta en práctica de este.

Seguramente el propio Freire también estaría de acuerdo con estas certeras palabras que escribió José Saramago (18 junio de 2010) en la última entrada que hizo en su blog:

Creo que en la sociedad actual nos falta filosofía. Filosofía como espacio, lugar, método de reflexión, que puede no tener un objetivo concreto, como la ciencia, que avanza para satisfacer objetivos. Nos falta reflexión, pensar, necesitamos el trabajo de pensar, y me parece que, sin ideas, no vamos a ninguna parte.

Sin duda la obra de Freire es una invitación a ejercitar la filosofía en el sentido aludido por Saramago, porque supone un espacio de libertad e igualdad. Un tiempo para la reflexión y la acción, una forma de entender no sólo lo educativo, sino la vida, con un sentido antropológico y ontológico preñado de ética y política.

La anterior reflexión nos lleva a un interesante artículo de reciente aparición, en el que la profesora Amilburu (2021) trata de poner en jaque la tendencia contemporánea de buir hacia delante en lo que se refiere a la educación. Esa huida, nos cuenta, está relacionada con el mandato posmoderno de la autosuficiencia, que encuentra un correlato en el mandato neoliberal de bacerse a uno mismo y el consiguiente descrédito de la tradición. En ese escenario, la educación parece mecerse en los brazos de un ilusorio propósito -crecer sin raíces- según el cual parecemos haber olvidado, como tan lúcidamente ha señalado Bellamy (2018), que «para conocer el mundo, e incluso para ser uno mismo, nos hacen falta las palabras de los otros»" (p. 110).

Esas palabras de los otros aluden en nuestro campo a la memoria pedagógica que cobra forma en la obra (intelectual y humana) de un incontable número de educadoras y educadores entre los que se encuentra la figura de Paulo Freire. A él dedicamos este número de Tendencias Pedagógicas justo el año en que se conmemora el centenario de su nacimiento.

Lejos de limitarnos a glosar sus méritos, nos ha parecido pertinente presentar el número recogiendo las anteriores reflexiones a propósito de la tradición y la trasmisión cultural, con el ánimo de poner sobre la mesa un asunto concreto: las relaciones que entablamos en el campo pedagógico con las tradiciones de pensamiento.

En un sentido general, nos dice Amilburu (2021), entendemos por tradición «una forma heredada de ver el mundo que comparte un grupo de personas y que responde a experiencias previas de diversa índole —familiares, culturales, científicas, religiosas, políticas, etc. $\longrightarrow$ (p. 41). Desde esa perspectiva, nos referimos aquí a tradiciones de pensamiento por analogía con otras nociones como escuelas o corrientes en el sentido de -y parafraseando a Amilburu-formas de ver el mundo que comparten un grupo de profesores $e$ investigadores y que responde a unas experiencias de indole cultural y científico.

Poner sobre la mesa, como decimos, nuestras relaciones con las tradiciones de pensamiento es una acción de resistencia ante la devaluación de la teoría -y otros contenidos culturales- en el terreno de la formación de profesionales de la educación (Esteban, 2019; Thoilliez, 2020). Y es que nos encontramos, fruto de la mercantilización lacerante de todas las esferas de la vida, con una apropiación de la figura de educadores y educadoras como María Montessori o el propio Freire. Así, convertidos en marca, puede que las nuevas generaciones conozcan antes a estos referentes de la pedagogía por aquellas citas célebres que encuentran recopiladas en sitios Web de dudoso valor o serigrafiadas en productos de merchandising; del mismo modo que llevamos décadas viendo al Che Guevara convertido en icono pop.

Lejos de querer trivializar el asunto, nos interesa por un lado reabrir la discusión intelectual acerca de la pregunta ya planteada por cuáles son nuestras relaciones con las tradiciones de pensamiento; por otro, preguntarnos por el sentido de cómo nos relacionamos con ellas respecto del estudio, la investigación y la docencia. 
Parece relativamente claro que estamos atrapados en el ojo del huracán de la ideología de la innovación. Una espiral que atrae hacia su centro el pensamiento y las prácticas, produciendo la sensación de que estamos gobernados por lo que podemos calificar -ácidamente- como la dictadura del quinquenio; refiriéndonos al dócil y acrítico modo en que hemos asumido que todo trabajo académico debe mantenerse actualizado y, fruto de eso, demandamos la consulta de los famosos «últimos 5 años». Sin embargo, la cuestión no se reduce a la fecha de los estudios y ensayos citados, sino a cómo estos, y otros precedentes, arraigan en campos del saber que tienen una historia detrás que es preciso conocer y en la que es necesario adentrarse para, a partir de ella, poder introducir la novedad que traen otros tiempos, otras sensibilidades, otras lecturas.

Estudiar de nuevo a Freire, releerlo, nos puede ayudar en este sentido, dándonos amplitud de miras, como hacen los clásicos; ofreciéndonos elementos de reflexión intemporales desde su contextualización e historicidad, porque van al centro, a lo importante, a lo sustantivo de lo pedagógico y las relaciones que lo vertebran, que lo sostienen.

\section{Reavivar la relación con los clásicos: el Freire que no caduca}

Como nos recuerda el profesor Bárcena (2021), «Es posible llegar a percibir, en la lectura de algunas grandes obras al menos, que lo que leemos parece estar hablando de nosotros también, de lo que nos pasa en nuestro tiempo y específicas circunstancias» (p. 145). A esas grandes obras las calificamos de clásicos, y poseen la capacidad de, como dice Gabilondo (2012) "pervivir y de transvivir en la historia" (p. 112). Algo que Lledó (2018) expresará de otra manera al sostener que un autor es clásico en la medida en que es

capaz de alimentar, inagotablemente, continuas interpretaciones y de provocar un diálogo con sus lectores para enriquecer su clausurada y, tantas veces, monótona soledad. Pero, al mismo tiempo, los clásicos sobreviven a esas interpretaciones y aparecen, de pronto, inalterados y libres, para fecundar nuestra propia libertad. (p. 121)

Leer clásicos en educación tiene que ver, por un parte, con leer educación en las carreras de educación y por parte de profesionales de la educación. Leer como estudio (Bárcena, 2020). Y leer a los clásicos en tanto que, como señala nuevamente Gabilondo (2012), hacerlo «es siempre reactivar el decir, hacer que un texto nos diga de nuevo» (pp. 112-113). En este sentido, el criterio profesional de educadoras y educadores necesita alimentarse del cuerpo de reflexiones que atesoramos y que arraigan de formas diversas y no siempre conciliables en el seno de distintas escuelas, corrientes o tradiciones. De acuerdo con esto, reivindicamos a Freire como un clásico de la pedagogía desde su valor ontológico, como pensador y activista que desafiaba el statu quo.

Conviene recordar con Steiner (Steiner y Ladjali, 2016), que lo clásico es siempre deudor de unas relaciones de poder, de una visión del mundo y de la fuerza para hacer esa visión preponderante. Freire, como clásico, debe reivindicarse sin las ataduras del canon. Debe estudiarse (o, mejor dicho, no debe dejar de estudiarse), precisamente, porque su potencia fue y es la de ofrecer una cosmovisión pedagógica con una proyección social y política de una fuerza epistemológica y axiológica apabullante, de una belleza lingüística inusual y de una firmeza llena de humildad. Por eso el centenario de su nacimiento es un magnífico -nuevo- pretexto para volver a sus libros e ideas; y es por eso por lo que sostenemos que Freire no caduca.

De hecho, si decimos que los clásicos hablan de nosotros y de nuestro tiempo, y si decimos que pueden llegar a fecundar nuestra libertad, llegamos al punto de preguntarnos por el alcance de tales potencialidades en relación con nuestro autor. Él mismo destacó en su Pedagogía de la Indignación que «La educación siempre es una especie de teoría del conocimiento puesta en práctica, es naturalmente política, tiene que ver con la pureza, nunca con el puritanismo, y es, en sí, una experiencia de belleza.» (Freire, 2001, p. 113).

Esta última cita pensamos que sintetiza el espíritu del Monográfico dedicado a Freire y de los magníficos artículos que lo componen. Queremos agradecer desde aquí cada una de las aportaciones, porque no sólo poseen a nuestro juicio un indudable valor académico y de compromiso con las ideas que representa Freire, sino porque suponen un homenaje a las mismas y a los valores que éste siempre defendió de forma coherente y apasionada. 


\section{Composición del número}

El número está compuesto por siete artículos, un conjunto plural de textos que dialogan con la obra de Freire desde perspectivas e intereses distintos, ofreciendo un interesante abanico de reflexiones que conectan con la obra de nuestro autor.

El primero de los trabajos, «A educação libertadora e o novo conservadorismo: a atualidade de Paulo Freire», firmado por Alexandre Silva Virginio (Universidade Federal do Rio Grande do Sul de Brasil), recupera las principales categorías del pensamiento de Freire con el propósito de poner sobre la mesa su valor a la hora de analizar el mundo contemporáneo y construir formas alternativas de vida y de pensamiento.

El segundo de los textos, «Repensando a Paulo Freire como pedagogo-educador social: elogio de un quehacer cívico, educativo y cultural (trans)formador», que viene bajo la firma del profesor José Antonio Caride (Universidad de Santiago de Compostela, España), nos propone mirar la figura de Freire haciendo énfasis en la Pedagogía y la Educación Social, repensando con ello sus aportaciones -conceptos, teoría y prácticas- en un ejercicio de reinvención, como el propio Freire pidió.

El tercer artículo, «Educar nuestra esperanza en tiempos de oscuridad: cómo continuar trabajando hacia la justicia social en un mundo capitalista neoliberal», que trae la firma de Luis Huerta-Charles (New Mexico State University, Estados Unidos) y Peter McLaren (Chapman University, Estados Unidos), pone en un primer plano la fuerza del pensamiento freireano a la hora de desvelar los mecanismos de poder que presentan el mundo como realidad dada. Para ello recupera, como un alegato, la educación de la esperanza, concibiéndola como una fuerza transformadora.

En el cuarto trabajo, «Freire como pedagogo intercultural: diálogo, alteridad y lectura crítica del mundo», Eduardo Vila, Eduardo Sierra y Victoria Álvarez (Universidad de Málaga, España), plantean una perspectiva poco explorada, la de Freire como pedagogo intercultural. El artículo presenta una reflexión que se vertebra desde la noción de sensibilidad intercultural, analizando aspectos del pensamiento freireano desde dicha perspectiva.

En el quinto artículo, «Concientización y criticismo. Aportaciones de Raymond Williams», Emilio Lucio-Villegas (Universidad de Sevilla, España) nos plantea un curioso ensayo en el que pone en relación la vida y la obra de Paulo Freire y la del pensador galés Raymond Williams. Para ello, identifica una serie de ejes transversales a la obra de ambos (la importancia de la cultura o la educación de personas adultas como práctica emancipatoria, entre otros), que a lo largo del texto explora con el propósito de fondo de generar posiciones de resistencia ante los envites neoliberales.

Nicolò Valenzano (Universidad de Turín, Italia), en el sexto artículo de nuestro número, con título «Influencias marxistas y personalistas en la antropología pedagógica de Paulo Freire», ofrece una lectura cruzada entre Freire y dos de sus influencias reconocidas: la filosofía marxista y el personalismo de Mounier, sosteniendo que la originalidad del pensamiento de Freire y su relevancia deben buscarse en la forma en que mezcló estas dos tradiciones.

Para finalizar, las profesoras Ester Caparrós (Universidad de Málaga, España) y Mayka García (Universidad de Cádiz, España) tratan en su texto «Éticas para la esperanza de una educación inclusiva», el séptimo del Monográfico, de hacer confluir el planteamiento de Freire sobre la ética y la libertad, con sus propias perspectivas acerca de la educación inclusiva. Para ello afianzan la ética freireana como una ética en la acción, inseparablemente vinculada a la práctica educativa.

\section{Un punto y seguido}

En un artículo de 2016, Michael Apple contaba lo siguiente:

Paulo Freire y yo, en muchos diálogos, quedábamos horas discutiendo la importancia, no sólo de intervenciones teóricas, sino también de la importancia crucial de la praxis, de intervenir en las vidas diarias de realidades culturales y pedagógicas y de dejar que estas intervenciones contesten (respondan) al trabajo político y teórico que se busca desarrollar. Desafortunadamente, muchos «teóricos críticos» de la educación se han olvidado de la necesidad de tal acción. La teoría «domina», con rara excepción, proveniente de las realidades institucionales y de comunidades reales, en luchas reales. Las luchas de afro-brasileños contra la subyugación no eran abstracciones para Freire. Él las veía como parte de las luchas necesarias contra la dominación. (...) Aquellos de nosotros que están comprometidos con políticas y prácticas educativas emancipatorias y antirracistas, serían perspicaces al dirigir su crítica no sólo a los efectos raciales sobre los mercados y estándares culturales, sino también 
para las «formas creativas» utilizadas por movimientos neo-liberales y neo-conservadores para convencer a las masas de que estas políticas son simplemente tecnologías neutras que nos ayudarán a hacer la educación más eficiente y eficaz. (Apple, 2016, p. 279)

Esta cita nos interpela sobre el diálogo que Freire mantiene abierto con educadoras y educadores, intelectuales y personas interesadas en la pedagogía y sus posibilidades transformadoras; e interesadas también en el valor del conocimiento teórico en sí, porque acaba teniendo proyección en los cambios necesarios desde criterios políticos y éticos, donde los derechos humanos son referentes ineludibles. Por eso es importante revisitar a Freire, porque con él podemos seguir aportando granitos de arena a una sociedad que imaginamos y deseamos vertebrada por la equidad, la justicia y la solidaridad.

\section{Referencias}

Amilburu, M. (2021). Conexiones en red con otros tiempos, espacios y generaciones. Roger Scruton, tradiciones y educación. Teoría de la Educación, Revista Interuniversitaria, 33(1), 3549. https://doi.org/10.14201/teri.23463

Apple, M. (2016). Expanding the dynamics of power: Freire and the politics of race in education. Revista e-Curriculum, 14(1), 277-295. Recuperado de: https://revistas.pucsp.br/index.php/curriculum/article/view/27355

Bárcena, F. (2021). Bárcena, F. (2021). Leer, un rapto del alma. Márgenes, Revista de Educación de la Universidad de Málaga, 2(2), 143-149. https://dx.doi.org/10.24310/mgnmar.v2i2.12829

Bellamy, F. X. (2018). Los desheredados. Por qué es urgente trasmitir la cultura. Encuentro.

Esteban, F. (2019). La universidad light. Un análisis de nuestra formación universitaria. Paidós.

Freire, P. (2001). Pedagogía de la indignación. Morata.

Gabilondo, Á. (2012). Darse a la lectura. RBA.

Lledó, E. (2018). Sobre la educación. Taurus.

Saramago, J. (18 de junio de 2010). Pensar, pensar. [publicación de blog] Recuperado de: https://cuaderno.josesaramago.org/68618.html

Steiner, G. y Ladjali, C. (2016). Elogio de la trasmisión (4ª edición). Siruela.

Thoilliez, B. (2020). "La teoría de la educación en España: 1 peligro, 2 reacciones, 1 propuesta". En E. S. Vila, J. E. Sierra y V. M. Martín (Coords) Teoría de la educación: docencia e investigación (1933). GEU. 